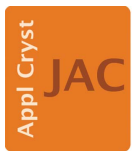

JOURNAL OF

APPLIED

CRYSTALLOGRAPHY

ISSN 1600-5767

Received 31 January 2017

Accepted 16 March 2017

Edited by A. J. Allen, National Institute of Standards and Technology, Gaithersburg, USA

Keywords: phosphors; energy transfer; photoluminescence; down-conversion; nanocrystals; orthovanadate.

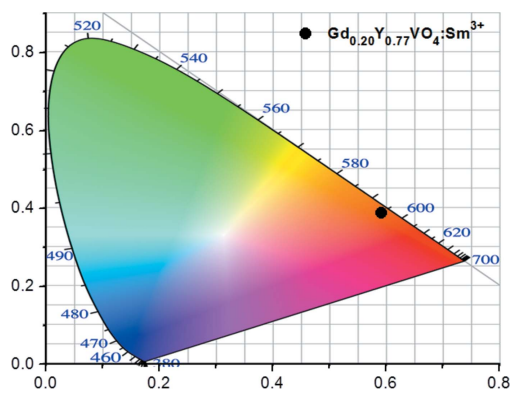

C 2017 International Union of Crystallography

\section{Appearance of efficient luminescence energy transfer in doped orthovanadate nanocrystals}

\author{
Swati Bishnoi, ${ }^{\mathrm{a}, \mathrm{b}}$ G. Swati, ${ }^{\mathrm{a}, \mathrm{b}}$ Paramjeet Singh, ${ }^{\mathrm{b}}$ V. V. Jaiswal, ${ }^{\mathrm{b}}$ Mukesh K. Sahu, \\ Vinay Gupta, $^{\mathrm{a}, \mathrm{b}}$ N. Vijayan ${ }^{\mathrm{a}, \mathrm{b}}$ and D. Haranath ${ }^{\mathrm{a}, \mathrm{b} *}$ \\ aAcademy of Scientific and Innovative Research, CSIR - National Physical Laboratory, Dr K. S. Krishnan Road, New Delhi \\ 110012, India, and ${ }^{\mathbf{b} C S I R}$ - National Physical Laboratory, Dr K. S. Krishnan Road, New Delhi 110 012, India. \\ *Correspondence e-mail: haranath@nplindia.org
}

This paper reports the detailed synthesis mechanism and the structural, morphological and optical characterization of ultraviolet $(\sim 311 \mathrm{~nm})$ excitable samarium doped gadolinium yttrium orthovanadate, $(\mathrm{Gd}, \mathrm{Y}) \mathrm{VO}_{4}: \mathrm{Sm}^{3+}$, nanocrystals. X-ray diffraction and Rietveld refinement studies confirmed that the synthesized samples crystallize in a tetragonal structure with I41/amd space group. The enhanced photoluminescence intensity of $(\mathrm{Gd}, \mathrm{Y}) \mathrm{VO}_{4}: \mathrm{Sm}^{3+}$ compared with the existing $\mathrm{YVO}_{4}: \mathrm{Sm}^{3+}$ phosphor clearly indicates the significant role of $\mathrm{Gd}^{3+}$ ions. This has been attributed to the sensitization of the ${ }^{6} P_{J}$ energy level of $\mathrm{Gd}^{3+}$ ions by energy transfer from orthovanadate $\left(\mathrm{VO}_{4}{ }^{3-}\right)$ ions and subsequent energy trapping by $\mathrm{Sm}^{3+}$ ions. The energy transfer from $\mathrm{VO}_{4}{ }^{3-}$ to $\mathrm{Sm}^{3+}$ via $\mathrm{Gd}^{3+}$ ions as intermediates and concentration quenching of $\mathrm{Gd}^{3+}$ luminescence are discussed in detail. The optical band gap of the as-prepared nanocrystals has been estimated using UV-vis-NIR absorption spectroscopy, which reveals a slightly higher band gap $(3.75 \mathrm{eV})$ for $\mathrm{YVO}_{4}$ as compared to $\mathrm{GdYVO}_{4}(3.50 \mathrm{eV})$. Furthermore, confocal microcopy, decay parameters and Commission Internationale de l'Eclairage chromatic coordinates have supplemented these studies, which established the suitability of these nanophosphors for achieving spectral conversion in silicon solar cells.

\section{Introduction}

Solar energy harvesting through photovoltaic (PV) technologies is one of the proficient routes to meet the rapidly growing energy demands of the world. A broad range of photovoltaic techniques for solar energy harvesting have been available for more than half a century (Hisatomi et al., 2014; X. Chen et al., 2012; H. M. Chen et al., 2012; Pinel et al., 2011; Braga et al., 2008; Zou et al., 2001). Nevertheless, solar energy capture via photovoltaic cells is still a costly issue. This cost is attributable to the low power conversion efficiencies of the existing solar cells, resulting from the spectral mismatch between the energy distribution of photons in the incident solar spectrum and the band gap of the constituent semiconductor material. Luminescent materials (phosphors) capable of converting a broad spectrum of UV radiation into photons of a particular wavelength are potential candidates for resolving the spectral mismatch issue of PV cells. Many phosphors based on oxides, silicates, vanadates, oxyfluorides etc. have been synthesized and studied with the aim of achieving spectral conversion in solar cells (Heng et al., 2016; Zhydachevskii et al., 2014; Wegh et al., 1999; Wei et al., 2011). Out of these available materials, orthovanadates such as $\mathrm{YVO}_{4}$ and $\mathrm{GdVO}_{4}$ have received considerable attention owing to their unique spectral properties, including narrow emission bandwidths, large Stokes 
shifts, high luminescence efficiencies and longer lifetimes (Som et al., 2016). Although there are many reports on $\mathrm{GdVO}_{4}$ and $\mathrm{YVO}_{4}$ based phosphors, there are very few reports on the composite (Gd,Y) $\mathrm{VO}_{4}$ based nanophosphors (Som et al., 2016; Kumari \& Manam, 2015; Chen et al., 2011; Wang et al., 2009). To the best of our knowledge, this is the first report on the synthesis, mechanism, and structural and photoluminescence (PL) characterization of $\mathrm{Sm}^{3+}$ doped $(\mathrm{Gd}, \mathrm{Y}) \mathrm{VO}_{4}$ based downconversion nanophosphors. We demonstrate the role of $\mathrm{Gd}^{3+}$ ions as intermediates in luminescence enhancement, supported by PL and time-resolved PL decay measurements. Since the optical properties of a doped orthovanadate system depend intimately on the local structure and bonding of the dopant cations, a detailed understanding of these factors is important from a device-engineering viewpoint. The insertion of the dopant acts as a perturbation of this well studied system. $\mathrm{Sm}^{3+}$ was selected as a representative rare-earth ion because its unique fluorescence properties, similar to those of $\mathrm{Eu}^{3+}$ ions, make it an ideal probe for local structure determination of the host crystal. As a research goal to pursue, we have successfully prepared highly luminescent $(\mathrm{Gd}, \mathrm{Y}) \mathrm{VO}_{4}: \mathrm{Sm}^{3+}$ nanophosphor powders that have distinctive photoluminescence properties. Herein, we report a new class of highly luminescent orthovanadate based nanophosphors that individually emit orange-red luminescence on exposure to $\sim 311 \mathrm{~nm}$ UV light. The advantages of the present protocol are numerous and include the following: (i) high surface-tovolume ratios with effective prevention of further aggregation of the nanophosphor particles, so as to exhibit a high luminescence yield; (ii) the profitability of size-quantized nanometre-sized $\mathrm{Gd}_{x} \mathrm{Y}_{1-x} \mathrm{VO}_{4}$ phosphor particles with higher redox potential, which in turn enhances the charge-transfer rates between the $\mathrm{Gd}^{3+}$ and $\mathrm{VO}_{4}{ }^{3-}$ network and the dopant $\left(\mathrm{Sm}^{3+}\right)$ ion by host-dopant interactions; and (iii) good dispersity and useful nanodimensions for possible coating over many substrates. Furthermore, the $\mathrm{Gd}^{3+}$ concentration has been optimized for achieving the brightest photoluminescence. The synthesized $(\mathrm{Gd}, \mathrm{Y}) \mathrm{VO}_{4}$ nanophosphors were characterized for their structural, morphological, optical and luminescence properties. A Rietveld refinement study of the X-ray diffraction data has been carried out to analyse the crystallographic data. The optical band gap of the samples has been approximated experimentally using UV-vis-NIR spectroscopy, which revealed a slightly higher band gap for $\mathrm{YVO}_{4}$ as compared to $(\mathrm{Gd}, \mathrm{Y}) \mathrm{VO}_{4}$ nanophosphors. In addition, we demonstrate that the $(\mathrm{Gd}, \mathrm{Y}) \mathrm{VO}_{4}: \mathrm{Sm}^{3+}$ compounds are excellent phosphors with high luminescence yields which are considered to be the best choices for achieving spectral conversion in silicon solar cells.

\section{Material and methods}

2.1. Synthesis of nanophosphors by co-precipitation and its detailed mechanism

$(\mathrm{Gd}, \mathrm{Y}) \mathrm{VO}_{4}: \mathrm{Sm}^{3+}$ nanophosphor samples were synthesized using the facile chemical co-precipitation technique. The $\mathrm{Gd}^{3+}$ concentration $(x)$ was varied from 0 to $80 \mathrm{~mol} \%$ and the $\mathrm{Sm}^{3+}$ concentration was fixed at $3 \mathrm{~mol} \%$, to achieve maximum photoluminescence emission under UV $(\sim 311 \mathrm{~nm})$ excitation. For a typical sample synthesis, stoichiometric amounts of nitrate (precursor) salts of yttrium, gadolinium and samarium were dissolved in aqueous media, under continuous stirring at room temperature $(\sim 298 \mathrm{~K})$. Details of the reaction mechanism are as follows.

Hydrolysis of the precursor salts gives rise to their respective hydroxides:

$$
\begin{gathered}
\mathrm{Gd}\left(\mathrm{NO}_{3}\right)_{3} \stackrel{+3 \mathrm{H}_{2} \mathrm{O}}{\longrightarrow} \mathrm{Gd}(\mathrm{OH})_{3}+3 \mathrm{HNO}_{3}, \\
\mathrm{Y}\left(\mathrm{NO}_{3}\right)_{3} \stackrel{+3 \mathrm{H}_{2} \mathrm{O}}{\longrightarrow} \mathrm{Y}(\mathrm{OH})_{3}+3 \mathrm{HNO}_{3}, \\
\mathrm{Sm}\left(\mathrm{NO}_{3}\right)_{3} \stackrel{+3 \mathrm{H}_{2} \mathrm{O}}{\rightarrow} \mathrm{Sm}(\mathrm{OH})_{3}+3 \mathrm{HNO}_{3} .
\end{gathered}
$$

Under continuous stirring at room temperature $(\sim 298 \mathrm{~K})$, ammonium metavanadate $\left(\mathrm{NH}_{4} \mathrm{VO}_{3}\right)$ was added dropwise. The metavanadate exists as a polymeric chain of $\mathrm{VO}_{4}{ }^{3-}$ units:

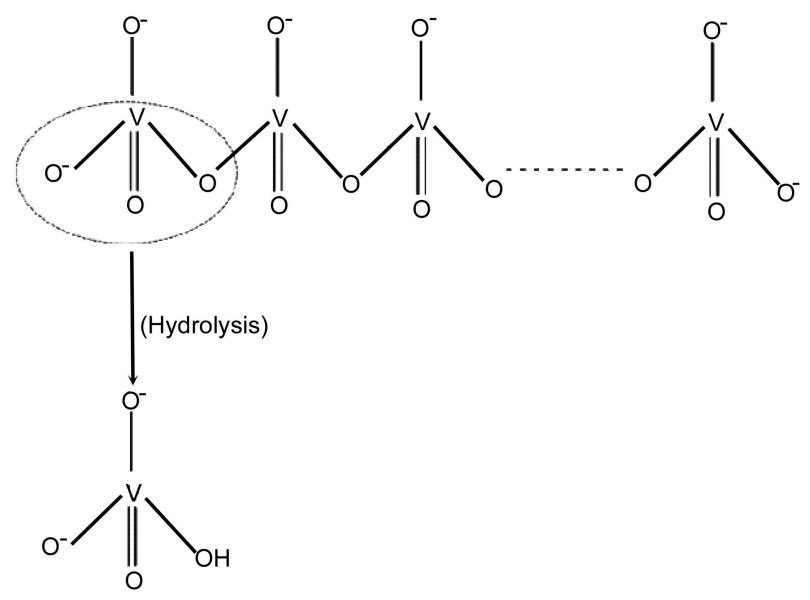

Terminal group $\mathrm{VO}_{4}{ }^{3-}$ units undergo hydrolysis in the presence of water, which generates $\mathrm{HVO}_{4}{ }^{2-}$ ions (acidic species). These ions do not eliminate their last $\mathrm{H}^{+}$ion owing to the 'common ion effect' caused by the strong acid $\mathrm{HNO}_{3}$ existing in the solution. Subsequently, $1 M \mathrm{NaOH}$ was added to the above solution, which reacts with $\mathrm{HNO}_{3}$ to form a salt as a side product. The corresponding chemical reaction is

$$
\mathrm{NaOH}+\mathrm{HNO}_{3} \longrightarrow \mathrm{NaNO}_{3} \text { (aqueous). }
$$

This salt was removed by repeated washing with demineralized water. The unreacted $\mathrm{NaOH}$ creates a basic medium $\mathrm{pH}>8$, which induces the reaction

$$
\begin{gathered}
\mathrm{HVO}_{4}{ }^{2-}+\mathrm{OH}^{-} \longrightarrow \underbrace{\mathrm{VO}_{4}{ }^{3-}}_{\text {(orthovanadate ion) }}+\mathrm{H}_{2} \mathrm{O}, \\
\mathrm{Gd}(\mathrm{OH})_{3}+\mathrm{Y}(\mathrm{OH})_{3}+\mathrm{Sm}(\mathrm{OH})_{3}+\mathrm{VO}_{4}{ }^{3-} \longrightarrow \\
\mathrm{Gd}_{x} \mathrm{Y}_{1-x} \mathrm{VO}_{4}: \mathrm{Sm} \quad \text { (precipitate). }
\end{gathered}
$$

The precipitation of hydroxides occurs owing to the decrease in their solubility in the presence of traces of $\mathrm{NaOH}$. In this process $\mathrm{VO}_{4}{ }^{3-}$ replaces $3 \mathrm{OH}^{-}$in the lattice stoichiometry to form the $\mathrm{Sm}^{3+}$ doped $(\mathrm{Gd}, \mathrm{Y}) \mathrm{VO}_{4}$ host lattice. The resulting 
precipitate was filtered off and washed several times with deionized water and ethanol, to remove the surface bound impurities and water molecules. The collected precipitate was dried in a vacuum oven and annealed at temperatures $>773 \mathrm{~K}$ for 1-3 h.

\section{Results and discussion}

\subsection{Crystal structure and phase analysis}

For phase identification, an X-ray diffraction (XRD) analysis was carried out on $\mathrm{Sm}^{3+}$ doped $(\mathrm{Gd}, \mathrm{Y}) \mathrm{VO}_{4}$ nanophosphors. Note that all the diffraction peaks matched very well with the standard JCPDS card (No. 85-2318; Kumari \& Manam, 2015). Fig. 1(a) shows the XRD spectra of the assynthesized and annealed $\mathrm{Gd}_{0.20} \mathrm{Y}_{0.77} \mathrm{VO}_{4}: \mathrm{Sm}(3 \%)$ nanophosphor samples along with the standard JCPDS spectrum. Annealing at $1073 \mathrm{~K}$ resulted in improved crystallization as compared to the as-synthesized nanophosphor samples. The crystal structure of $\mathrm{Gd}_{0.20} \mathrm{Y}_{0.77} \mathrm{VO}_{4}: \mathrm{Sm}^{3+}(3 \%)$ was confirmed and the cell parameters were calculated using Rietveld analysis as shown in Fig. 1(b). The phosphor crystallizes in a tetragonal structure (space group I41/amd) with the lattice constants as described in Table 1. A schematic of the structure of the $\mathrm{GdYVO}_{4}$ phosphor is shown in Fig. 1(c).

\subsection{Band gap calculations}

The optical band gaps of $\mathrm{YVO}_{4}: \mathrm{Sm}^{3+}$ and $\mathrm{Gd}_{0.20} \mathrm{Y}_{0.77} \mathrm{VO}_{4}$ : $\mathrm{Sm}^{3+}$ were estimated using an empirical formula known for direct band gap materials as follows:

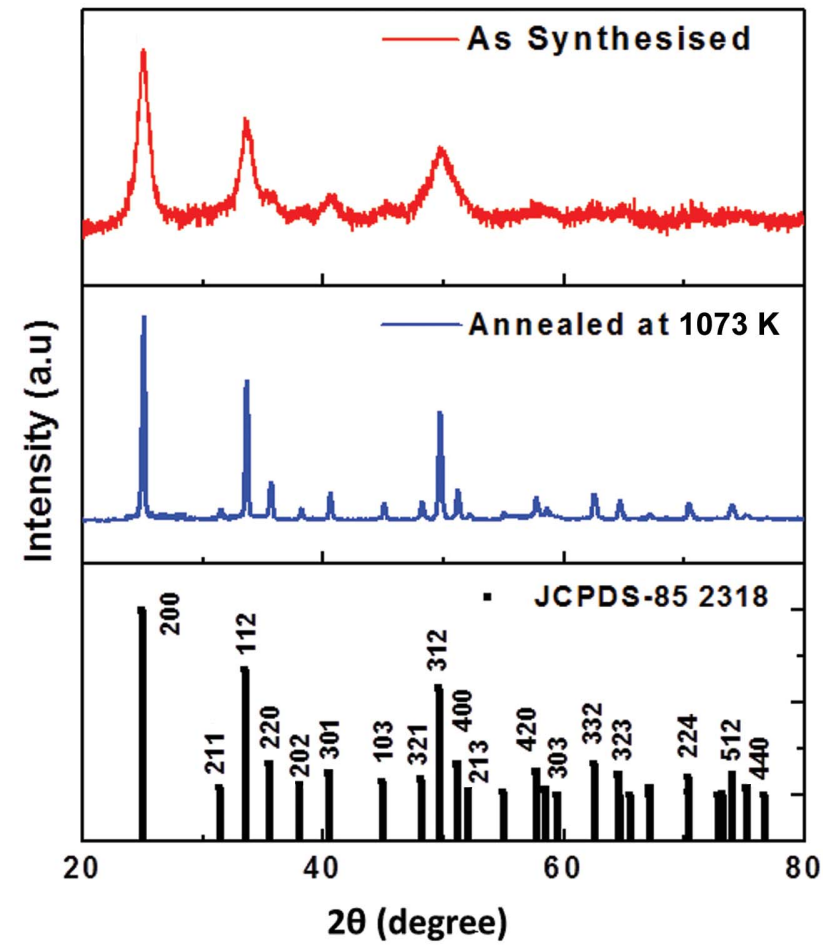

(a)
Table 1

Cell parameters of $\mathrm{Sm}^{3+}$ doped $\mathrm{Gd}_{0.20} \mathrm{Y}_{0.77} \mathrm{VO}_{4}$ nanophosphor calculated using Rietveld analysis.

\begin{tabular}{lllc}
\hline Atom & $X$ & $Y$ & $Z$ \\
\hline $\mathrm{O}$ & 0.0000 & 0.93874 & 1.46379 \\
$\mathrm{~V}$ & 0.0000 & 0.96521 & 0.5363 \\
$\mathrm{Gd}$ & 0.0000 & 0.68983 & 0.42824 \\
$\mathrm{Y}$ & 0.0000 & 0.0501 & -0.04051 \\
& & & \\
$a=7.1624 \AA$ & $\alpha=90^{\circ}$ & Cell volume $=323.9536 \AA^{3}$ & $R_{\mathrm{p}}=11.70$ \\
$b=7.1624 \AA$ & $\beta=90^{\circ}$ & & $R_{\mathrm{wp}}=8.10$ \\
$c=6.3148 \AA$ & $\gamma=90^{\circ}$ & & $R_{\mathrm{e}}=7.44$ \\
& & & $\chi^{2}=2.49$ \\
\hline
\end{tabular}

$$
(\alpha h v)^{2}=A\left(h v-E_{\mathrm{g}}\right)
$$

where $A$ is a constant that depends on the transition probability, $E_{\mathrm{g}}$ is the optical band gap energy, $h$ is Planck's constant, $v$ is the frequency and $\alpha$ is the absorption coefficient of the material. The optical band gap of the samples was calculated by extrapolating a straight line from the $(\alpha h v)^{2}$ versus energy $\left(E_{\mathrm{g}}\right)$ plot (Figs. $2 a$ and $2 b$ ). The band gap values estimated for $\mathrm{YVO}_{4}$ and $(\mathrm{Gd}, \mathrm{Y}) \mathrm{VO}_{4}$ are 3.75 and $3.50 \mathrm{eV}$,

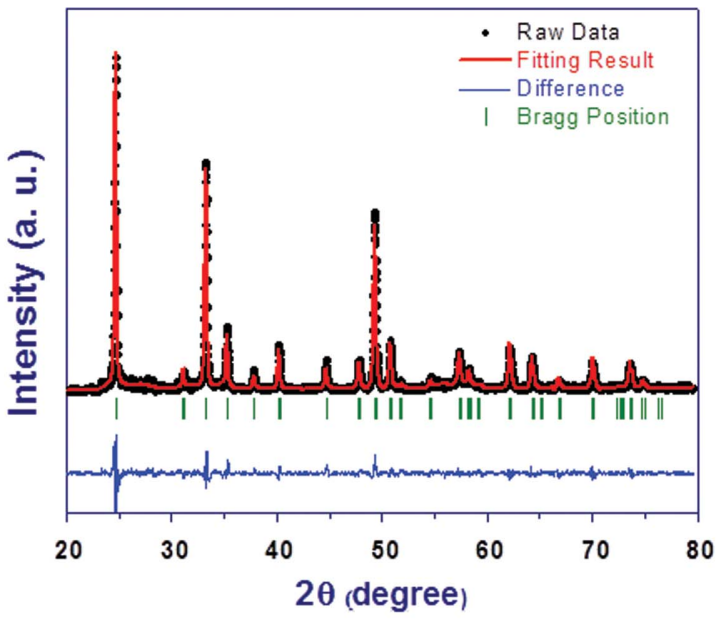

(b)

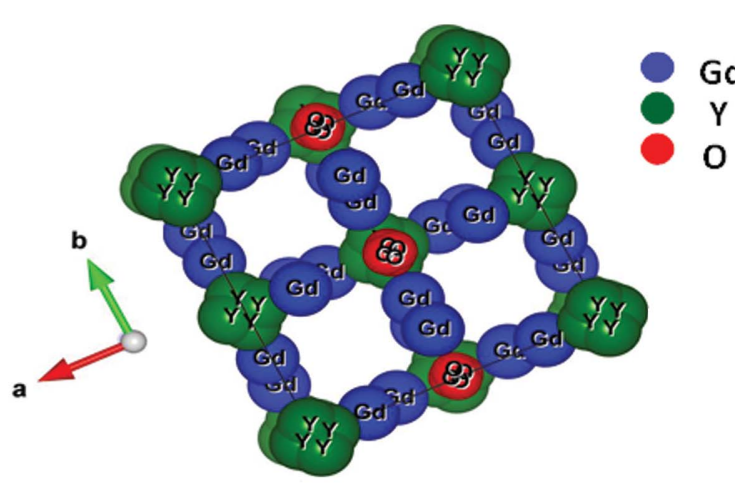

(c)

Figure 1

(a) XRD pattern of the $\mathrm{Gd}_{0.20} \mathrm{Y}_{0.77} \mathrm{VO}_{4}$ samples as synthesized by the co-precipitation technique and annealed at $1073 \mathrm{~K}$. (b) Rietveld refinement of the XRD data of the $\mathrm{Gd}_{0.20} \mathrm{Y}_{0.77} \mathrm{VO}_{4}$ sample annealed at $1073 \mathrm{~K}$. The black dots and red line represent the observed and fitted data, respectively. The blue line represents the difference between the observed and fitted data. (c) A schematic representation of the structure of $\mathrm{GdYVO}_{4}$. 
respectively. The lowering of the band gap of $(\mathrm{Gd}, \mathrm{Y}) \mathrm{VO}_{4}$ as compared to $\mathrm{YVO}_{4}$ is attributed to the fact that the $\mathrm{Gd}^{3+}$ ions form some metastable states between the valence band and conduction band (Som et al., 2016).

\subsection{Morphological and elemental analysis}

The morphology of the $\mathrm{Gd}_{0.20} \mathrm{Y}_{0.77} \mathrm{VO}_{4}: \mathrm{Sm}^{3+}$ particles annealed at $1073 \mathrm{~K}$ was investigated using scanning electron microscopy (SEM). The sample consists of homogenous aggregates of truncated spherical particles. The energy dispersive X-ray analysis (EDAX) spectrum along with the elemental composition is shown in Fig. 3(a).

\subsection{Photoluminescence analysis}

The photoluminescence (PL) emission spectra of the host lattices $\mathrm{YVO}_{4}$ and $\mathrm{Gd}_{0.20} \mathrm{Y}_{0.77} \mathrm{VO}_{4}$ excited at $\sim 311 \mathrm{~nm}$ are shown in Fig. 4(a). The spectrum shows a broad band PL peaking in the blue $(\sim 450 \mathrm{~nm})$ region. The PL excitation and emission spectra of the vanadate samples with optimized $\mathrm{Sm}^{3+}$ and $\mathrm{Gd}^{3+}$ ion concentrations are shown in Figs. $4(b)$ and $4(c)$.

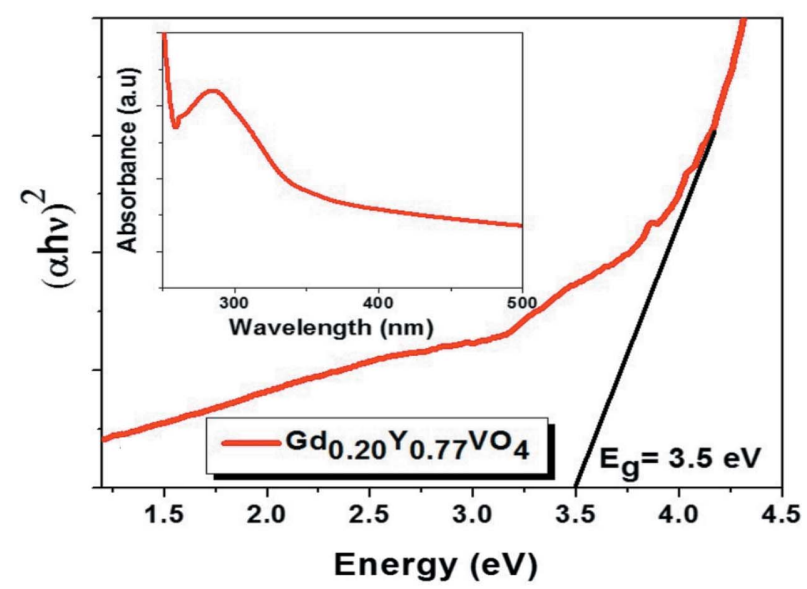

(a)

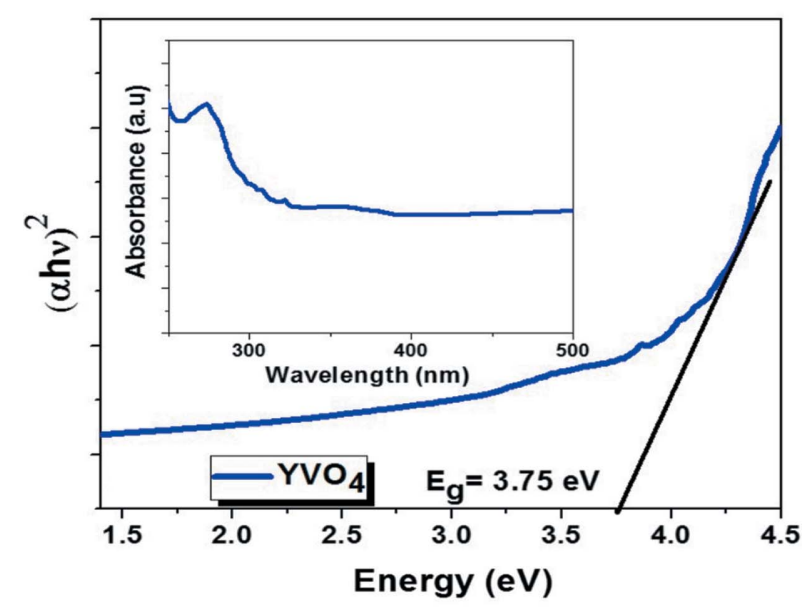

(b)

Figure 2

$(\alpha h v)^{2}$ versus energy plot for the determination of the optical band gap of (a) $\mathrm{Gd}_{0.20} \mathrm{Y}_{0.77} \mathrm{VO}_{4}: \mathrm{Sm}^{3+}$ and $(b) \mathrm{YVO}_{4}: \mathrm{Sm}^{3+}$ samples. Insets in both figures show their corresponding UV-vis-NIR absorption spectrum.
At $311 \mathrm{~nm}$ excitation, three main intensity peaks located at 563, 598 and $644 \mathrm{~nm}$ are observed, which are due to the ${ }^{4} G_{5 / 2} \rightarrow{ }^{6} H_{5 / 2},{ }^{4} G_{5 / 2} \rightarrow{ }^{6} H_{7 / 2}$ and ${ }^{4} G_{5 / 2} \rightarrow{ }^{6} H_{9 / 2}$ transitions of $\mathrm{Sm}^{3+}$ ions. In the emission spectra, the splitting of emission lines of $\mathrm{Sm}^{3+}$ into several lines is due to the crystal field splitting, which shows that $\mathrm{Sm}^{3+}$ ions are occupying the lowsymmetry sites in the lattice. The emission corresponding to the ${ }^{4} G_{5 / 2} \rightarrow{ }^{6} H_{7 / 2}$ transition has the highest intensity (598 nm) among the emission peaks as it satisfies the selection rule $\Delta J=$ \pm 1 (allowed transition). The transition ${ }^{4} G_{5 / 2} \rightarrow{ }^{6} H_{5 / 2}$, which is a magnetic dipole (m.d.) in nature, follows the first condition $(\Delta J=0)$. The next transition ${ }^{4} G_{5 / 2} \rightarrow{ }^{6} H_{7 / 2}(\Delta J= \pm 1)$ is again an (m.d.)-allowed one but is dominated by an electric dipole (e.d.) transition. Therefore, it is partly an m.d. and partly an e.d. type transition. The higher intensity of the peak at $598 \mathrm{~nm}$, as compared to that at $648 \mathrm{~nm}$ (m.d. transition), signifies the more asymmetric nature of the trivalent $\mathrm{Sm}^{3+}$ ions and gives a measure of the degree of distortion from the inversion symmetry of the local environment of the $\mathrm{Sm}^{3+}$ ion in the host. Therefore, the high intensity of the e.d. transition $(598 \mathrm{~nm})$ as compared to the m.d. transition $(648 \mathrm{~nm})$ reveals strong electric fields of low symmetry at the $\mathrm{Sm}^{3+}$ ions.

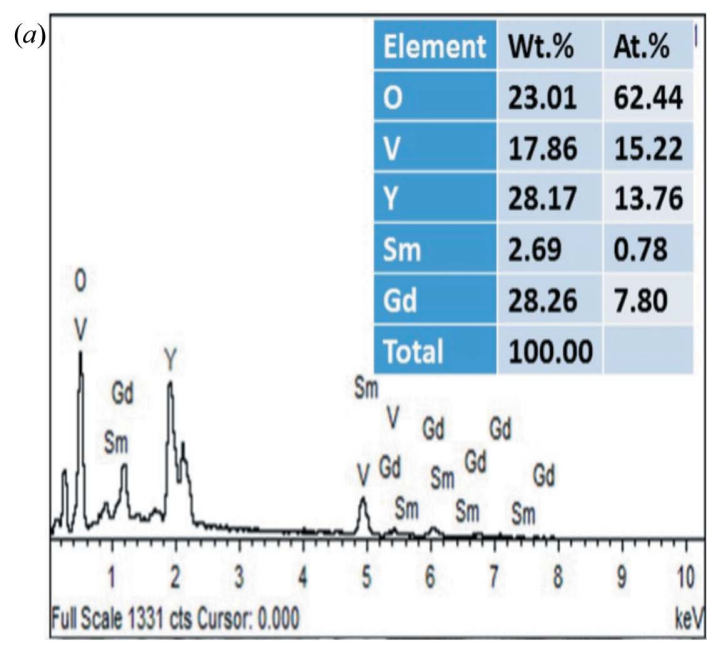

(b)

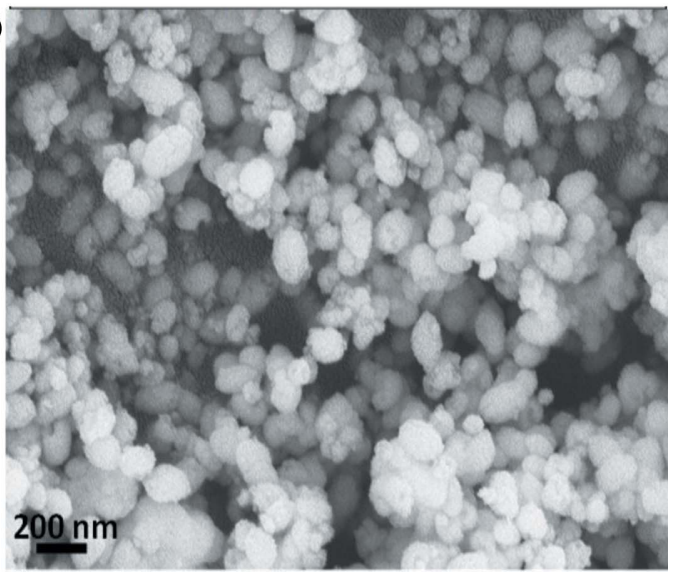

Figure 3

(a) A representative EDAX spectrum of a $\mathrm{Gd}_{x} \mathrm{Y}_{1-x} \mathrm{VO}_{4}: \mathrm{Sm}^{3+}(3 \%)$ sample, showing the presence of $\mathrm{Sm}^{3+}$ in the material along with the elemental composition. (b) SEM micrograph of a $\mathrm{Gd}_{x} \mathrm{Y}_{1-x} \mathrm{VO}_{4}: \mathrm{Sm}^{3+}$ nanophosphor annealed at $1073 \mathrm{~K}$. 
In the excitation spectra of Fig. 4(b), the excitation peak at $311 \mathrm{~nm}$ is attributed to the symmetry-allowed ${ }^{1} A_{1} \rightarrow{ }^{1} T_{2}\left(t_{1} \rightarrow\right.$ $2 e$ ) absorption of the $\mathrm{VO}_{4}{ }^{3-}$ unit, signifying electron transfer from oxygen $2 p$ states to the empty $d$ states of the vanadium ion (Liu et al., 2012; Yang et al., 2011; Liu et al., 2006; Ronde \& Blasse, 1978; Krumpel et al., 2009). The excitation spectrum reveals that in the case of $\mathrm{Gd}_{0.20} \mathrm{Y}_{0.77} \mathrm{VO}_{4}: \mathrm{Sm}^{3+}$ the charge transfer band (CTB) at $\sim 311 \mathrm{~nm}$ is quite dominant as compared to the spectrum of $\mathrm{YVO}_{4}$. This supports the contribution of the $\mathrm{Gd}^{3+}$ ion in the charge transfer phenomenon. The optical and corresponding confocal fluorescence images of $\mathrm{Gd}_{0.20} \mathrm{Y}_{0.77} \mathrm{VO}_{4}: \mathrm{Sm}^{3+}(3 \%)$ excited by UV laser $(375 \mathrm{~nm})$ light are shown in Figs. 5(a) and 5(b). Furthermore, the PL spectra shown in Fig. 5(c) reveal that the emission intensity of $\mathrm{Gd}_{0.20} \mathrm{Y}_{0.77} \mathrm{VO}_{4}: \mathrm{Sm}^{3+}$ is higher than that of $\mathrm{YVO}_{4}: \mathrm{Sm}^{3+}$ (for the optimized $\mathrm{Sm}^{3+}$ concentration). Actually, in $\mathrm{Gd}_{x} \mathrm{Y}_{1-x} \mathrm{VO}_{4}: \mathrm{Sm}$, the reason behind the enhanced CTB and emission intensity is probably the efficient energy transfer from the $\mathrm{VO}_{4}{ }^{3-}$ network to $\mathrm{Sm}^{3+}$ ions mediated by $\mathrm{Gd}^{3+}$ ions. Under $311 \mathrm{~nm}$ excitation, in the $\mathrm{VO}_{4}{ }^{3-}$ unit the symmetryallowed ${ }^{1} A_{1} \rightarrow{ }^{1} T_{2}$ absorption occurs Thereafter, two possibilities may arise, viz. either the $\mathrm{VO}_{4}{ }^{3-}$ unit transfers its excitation energy to the activator $\mathrm{Sm}^{3+}$ ion or it relaxes to the ground state with the PL emission of blue light. In $\mathrm{YVO}_{4}: \mathrm{Sm}^{3+}$ the intensity of blue PL emission is higher than that in $\mathrm{Gd}_{0.20} \mathrm{Y}_{0.77} \mathrm{VO}_{4}: \mathrm{Sm}^{3+}$, while the intensity of orange-red PL emission is lower (see Figs. $4 a$ and $5 c$ ), indicating efficient

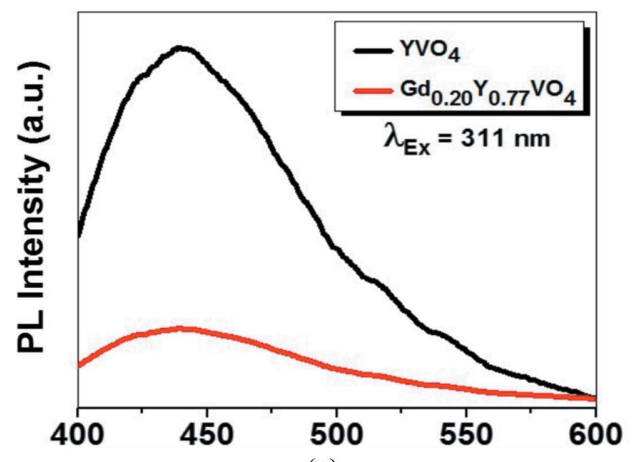

(a)

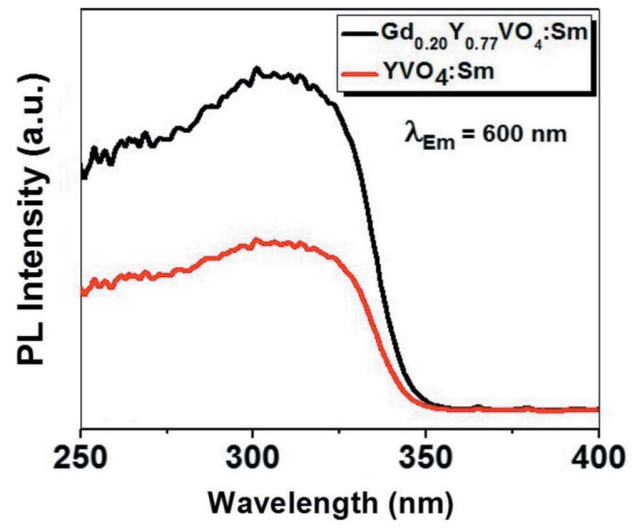

(b) energy transfer (ET) from $\mathrm{VO}_{4}{ }^{3-}$ to $\mathrm{Sm}^{3+}$ in the case of $\mathrm{Gd}_{0.20} \mathrm{Y}_{0.77} \mathrm{VO}_{4}$. The reason behind the enhanced PL emission intensity in the case of $\mathrm{Gd}_{x} \mathrm{Y}_{1-x} \mathrm{VO}_{4}: \mathrm{Sm}^{3+}$ is that the ET from the $\mathrm{VO}_{4}{ }^{3-}$ unit is effectively sensitizing the ${ }^{6} P_{J}$ states of $\mathrm{Gd}^{3+}$ ions because of the partial overlap between the $\mathrm{VO}_{4}{ }^{3-}$ emission and ${ }^{8} S_{7 / 2}{ }^{6} P_{J}$ absorption of $\mathrm{Gd}^{3+}$, and from ${ }^{6} P_{J}$ states the energy is transferred to the $\mathrm{Sm}^{3+}$ ions, resulting in an efficient orange-red PL emission (Tian et al., 2008). Apart from this, in the PL emission spectra no peak corresponding to the ${ }^{6} P_{J^{-}}$ ${ }^{8} S_{7 / 2}$ transition (i.e. $\sim 311 \mathrm{~nm}$ ) was observed, indicating that $\mathrm{Gd}^{3+}$ ions are transferring the excitation energy to the $\mathrm{Sm}^{3+}$ ions instead of undergoing ${ }^{6} \mathrm{P}_{J}-\mathrm{S}_{7 / 2}$ transition (Tian et al., 2008).

Moreover, in the $\mathrm{Gd}_{0.20} \mathrm{Y}_{0.77} \mathrm{VO}_{4}$ host, the blue PL emission corresponding to the $\mathrm{VO}_{4}{ }^{3-}$ ion transition is significantly reduced as compared to that for $\mathrm{YVO}_{4}$, indicating that the excitation energy of the $\mathrm{VO}_{4}{ }^{3-}$ units is transferred to $\mathrm{Gd}^{3+}$ ions. Actually, the PL emission spectra shown in Fig. 4(a) are those of undoped $\mathrm{YVO}_{4}$ and $\mathrm{Gd}_{0.20} \mathrm{Y}_{0.77} \mathrm{VO}_{4}$ recorded in the range 400-600 $\mathrm{nm}$ without the dopant $\mathrm{Sm}^{3+}$ ions. Under UV $(311 \mathrm{~nm})$ excitation, the blue emission (which is actually due to the ${ }^{3} T_{1} \rightarrow{ }^{1} A_{1}$ transition of the $\mathrm{VO}_{4}{ }^{3-}$ ion) is stronger in $\mathrm{YVO}_{4}$, which signifies that in the case of undoped $\mathrm{YVO}_{4}$ all the excitation energy absorbed by the $\mathrm{VO}_{4}{ }^{3-}$ ions is released as blue emission due to the ${ }^{3} T_{1} \rightarrow{ }^{1} A_{1}$ transitions of the $\mathrm{VO}_{4}{ }^{3-}$ ion. When $\mathrm{Gd}^{3+}$ ions are introduced into the lattice, the blue emission intensity is reduced because all the excitation energy absorbed by the $\mathrm{VO}_{4}{ }^{3-}$ ions is further transferred to the $\mathrm{Gd}^{3+}$ ions, and hence, in the case of undoped $\mathrm{Gd}_{0.20} \mathrm{Y}_{0.77} \mathrm{VO}_{4}$, all the excitation energy absorbed by the $\mathrm{VO}_{4}{ }^{3-}$ ion is not released as blue emission. Part of this excitation energy is transferred to the $\mathrm{Gd}^{3+}$ ions, hence lowering the intensity of the corresponding blue emission. But when $\mathrm{Sm}^{3+}$ ions are added into

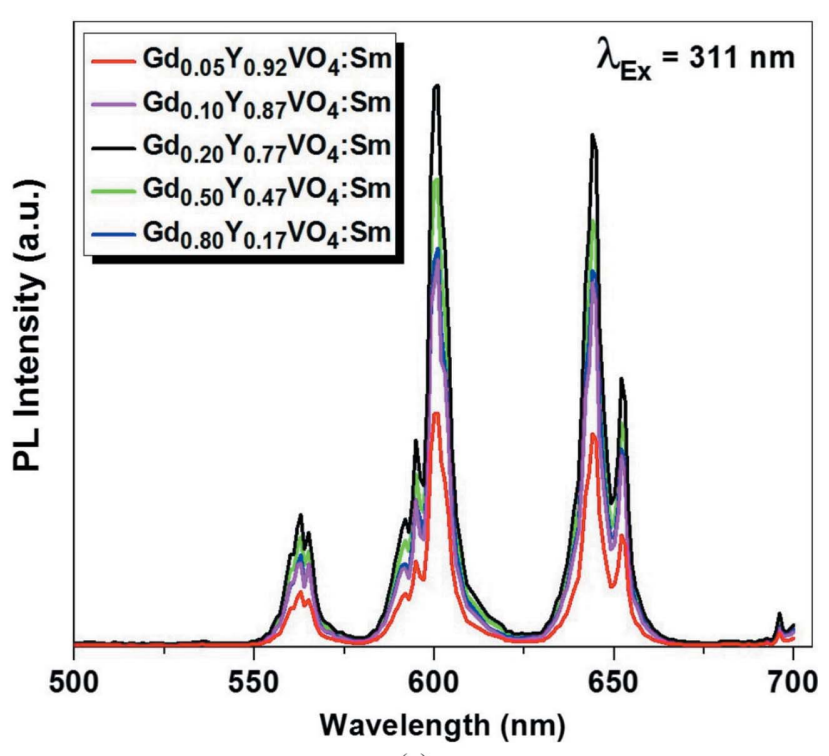

(c)

Figure 4

(a) The PL emission spectra of $\mathrm{YVO}_{4}$ and $\mathrm{Gd}_{0.20} \mathrm{Y}_{0.77} \mathrm{VO}_{4}$ host lattices in the range 400-600 nm under $311 \mathrm{~nm}$ excitation. (b) PL excitation spectra of $\mathrm{Gd}_{0.20} \mathrm{Y}_{0.77} \mathrm{VO}_{4}: \mathrm{Sm}^{3+}$ and $\mathrm{YVO}_{4}: \mathrm{Sm}^{3+}$ nanophosphors recorded at $600 \mathrm{~nm}$ emission. (c) PL emission spectra of $\mathrm{Gd}_{x} \mathrm{Y}_{1-x} \mathrm{VO}_{4}: \mathrm{Sm}^{3+}(x=0.05$ to 0.80$)$ samples annealed at $1073 \mathrm{~K}$ registered at $311 \mathrm{~nm}$ excitation with the concentration of Sm fixed at 0.03 moles for all the samples. 
the lattice, the $\mathrm{Gd}^{3+}$ ions further transfer the excitation energy to the $\mathrm{Sm}^{3+}$ ions, resulting in an enhanced orange-red emission in $(\mathrm{Gd}, \mathrm{Y}) \mathrm{VO}_{4}: \mathrm{Sm}$ as compared to $\mathrm{YVO}_{4}: \mathrm{Sm}$ samples. This was performed to establish the role of $\mathrm{Gd}^{3+}$ ions as intermediates in the energy transfer phenomenon between the $\mathrm{VO}_{4}{ }^{3-}$ ions and $\mathrm{Sm}^{3+}$ ions. The results signify that, in $(\mathrm{Gd}, \mathrm{Y}) \mathrm{VO}_{4}: \mathrm{Sm}$, the excitation energy absorbed by the $\mathrm{VO}_{4}{ }^{3-}$ ions is first transferred to the intermediate $\mathrm{Gd}^{3+}$ ions and then finally to the $\mathrm{Sm}^{3+}$ ions. Under UV excitation of $\mathrm{Gd}_{x} \mathrm{Y}_{1-x} \mathrm{VO}_{4}$ compounds, three possible mechanisms affecting luminescence are (i) the sensitization of $\mathrm{Gd}^{3+}\left({ }^{6} P_{J}\right)$ levels by $\mathrm{VO}_{4}{ }^{3-}$ energy transfer; (ii) migration of excitation energy between $\mathrm{Gd}^{3+}$ ions, resulting in enhanced non-radiative transitions; and (iii) the trapping of the excitation energy from $\mathrm{Gd}^{3+}$ ions by dopant $\left(\mathrm{Sm}^{3+}\right)$ ions.

When a small number of $\mathrm{Gd}^{3+}$ ions are doped into the lattice, they may occupy the lattice sites, but when the concentration of $\mathrm{Gd}^{3+}$ is higher than the optimum, this results in shrinking of the unit cell, which in turn results in migration of excitation energy between $\mathrm{Gd}^{3+}$ ions (hopping), thus reducing the corresponding $\mathrm{Sm}^{3+}$ ion emission (Juan et al., 2014). Hence, when the concentration of $\mathrm{Gd}^{3+}$ ions is higher than the optimum, the excitation energy is not transferred to $\mathrm{Sm}^{3+}$ ions; it migrates from one $\mathrm{Gd}^{3+}$ ion to another, resulting in reduced emission intensity, as shown in Fig. 6. Moreover,
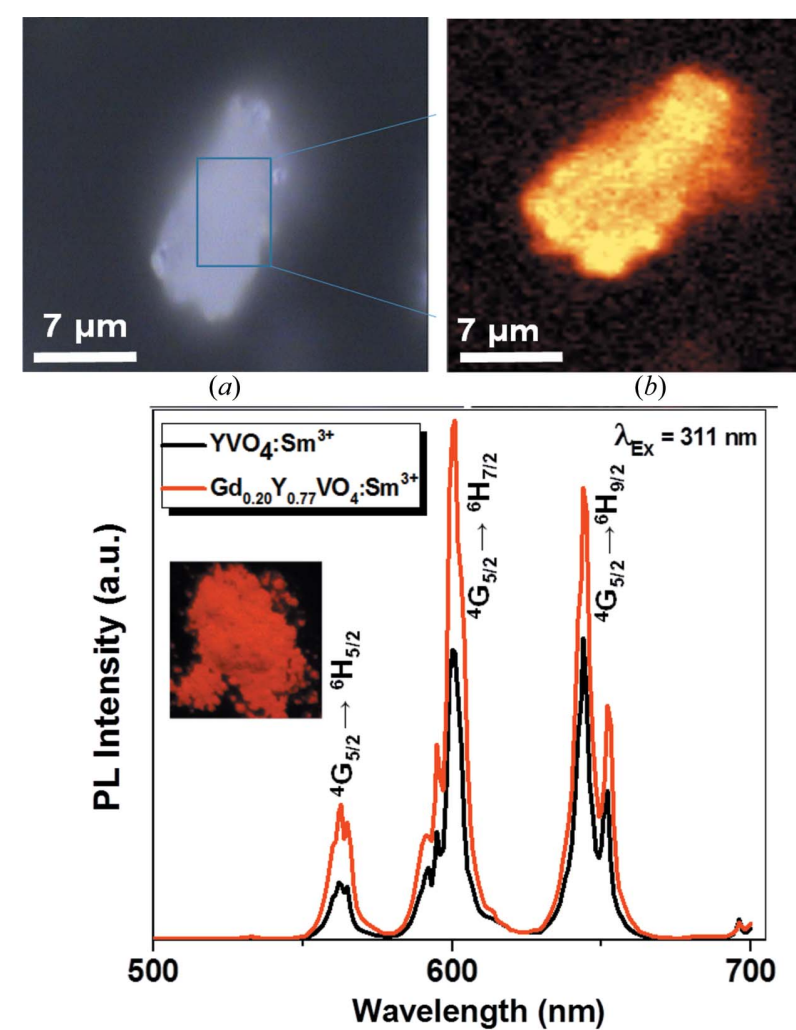

(c)

Figure 5

$\mathrm{Gd}_{0.20} \mathrm{Y}_{0.77} \mathrm{VO}_{4}: \mathrm{Sm}^{3+}(3 \%)$ : (a) optical image and (b) confocal fluorescence image under UV laser $(375 \mathrm{~nm})$ light excitation. (c) PL emission spectra of $\mathrm{Sm}^{3+}$ doped $\mathrm{YVO}_{4}$ and $\mathrm{Gd}_{0.20} \mathrm{Y}_{0.77} \mathrm{VO}_{4}$ samples under $311 \mathrm{~nm}$ excitation. The inset shows an image of orange-red emitting $\mathrm{Gd}_{0.20} \mathrm{Y}_{0.77} \mathrm{VO}_{4}: \mathrm{Sm}^{3+}$ (3\%) nanophosphor under UV (370 nm) light. addition of $\mathrm{Gd}^{3+}$ into the $\mathrm{YVO}_{4}$ lattice not only affects the crystal structure but also affects the generated crystal field, which affects the $\mathrm{Sm}^{3+}$ emission intensity drastically (Kumari $\&$ Manam, 2015). The doping of $\mathrm{Gd}^{3+}$ ions in addition slightly changes the volume of the unit cell in the crystal and thereby improves the energy transfer efficiency to $\mathrm{Sm}^{3+}$ ions, and eventually increases the fluorescence emission. Thus, the fluorescence emission could be adjusted by $\mathrm{Gd}^{3+}$ ion doping. The $\mathrm{Gd}^{3+}$ concentration was varied with $x=0,0.05,0.10,0.20$, 0.50 and 0.80 , i.e. from 0 to $80 \mathrm{~mol} \%$. The Gd concentration $x=$ $20 \mathrm{~mol} \%$ generates the most favourable crystal environment for the $\mathrm{Sm}^{3+}$ ion and hence the maximum $\mathrm{PL}$ emission intensity is observed for the $\mathrm{Gd}_{0.20} \mathrm{Y}_{0.77} \mathrm{VO}_{4}: \mathrm{Sm}^{3+}(3 \%)$ phosphor under UV excitation (Kumari \& Manam, 2015).

\subsection{Time-resolved photoluminescence decay analysis}

The intermediate role of $\mathrm{Gd}^{3+}$ ions in energy transfer has in addition been established using time-resolved PL, also known as lifetime decay measurements. Fig. 7 shows the decay curves of $\mathrm{Sm}^{3+}$ doped $\mathrm{Gd}_{0.20} \mathrm{Y}_{0.77} \mathrm{VO}_{4}$ and $\mathrm{YVO}_{4}$ samples under $311 \mathrm{~nm}$ excitation. Luminescence decay measurements are used for establishing energy transfer mechanisms and

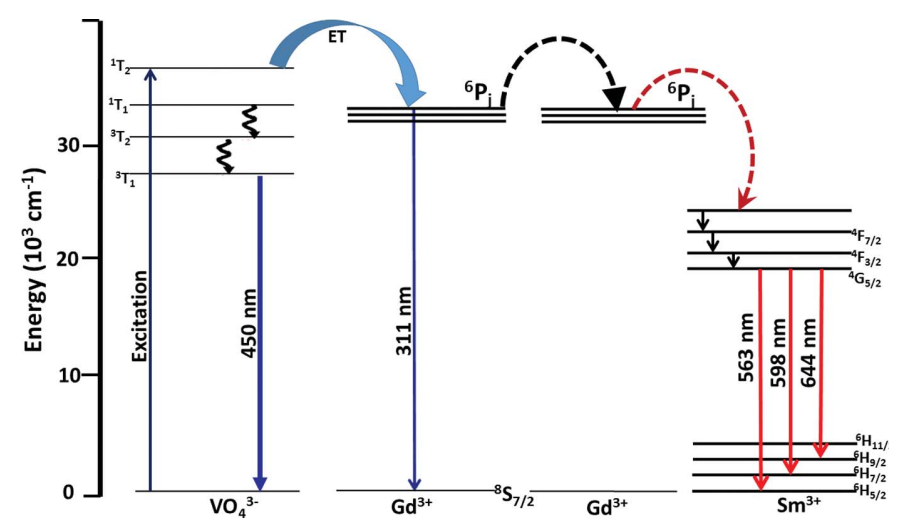

Figure 6

Energy level diagram showing the energy transfer mechanism in $\mathrm{Gd}_{x} \mathrm{Y}_{1-x} \mathrm{VO}_{4}: \mathrm{Sm}^{3+}$ samples with $\mathrm{Gd}^{3+}$ ions as intermediates.

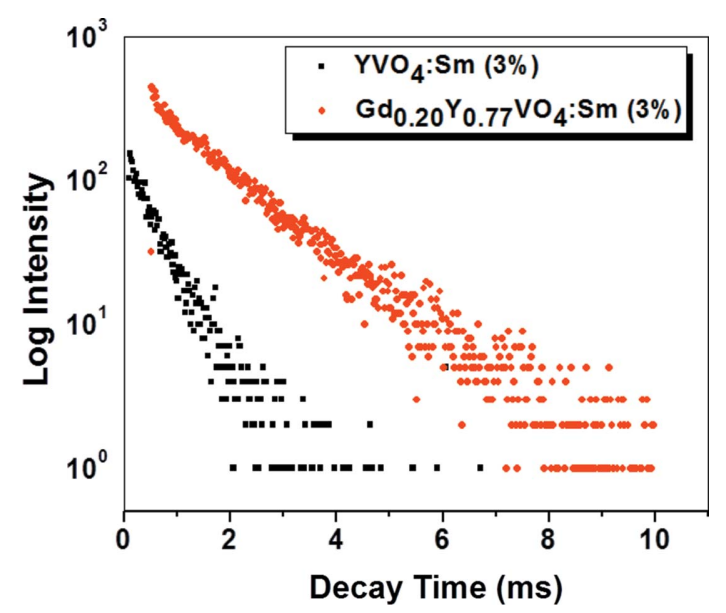

Figure 7

Time-resolved photoluminescence decay curve of $\mathrm{Sm}^{3+}$ doped $\mathrm{YVO}_{4}$ and $\mathrm{Gd}_{0.20} \mathrm{Y}_{0.77} \mathrm{VO}_{4}$ nanophosphor samples. 
Table 2

Decay parameters of $\mathrm{Sm}^{3+}$ doped $\mathrm{YVO}_{4}$ and $\mathrm{Gd}_{0.20} \mathrm{Y}_{0.77} \mathrm{VO}_{4}$ nanophosphor samples generated from the curve fitting.

\begin{tabular}{lll}
\hline Sample code & $\tau_{1}(\mathrm{~ms})$ & $\tau_{2}(\mathrm{~ms})$ \\
\hline $\mathrm{YVO}_{4}: \mathrm{Sm}^{3+}(3 \%)$ & 0.025 & 0.44 \\
$\mathrm{Gd}_{0.20} \mathrm{Y}_{0.77} \mathrm{VO}_{4}: \mathrm{Sm}^{3+}(3 \%)$ & 0.025 & 0.529 \\
\hline
\end{tabular}

luminescence quenching phenomena. The double exponential decay behaviour of the activator is often observed when the excitation energy is transferred from the donor (Shen et al., 2005). The resulting time-resolved PL decay curves were fitted via a multiexponential equation:

$$
I(t)=I_{0}+A_{1} \exp \left(-t / \tau_{1}\right)+A_{2} \exp \left(-t / \tau_{2}\right)
$$

where $\tau_{1}$ and $\tau_{2}$ are the fast and slow components of the luminescent lifetimes, and $A_{1}$ and $A_{2}$ are the respective fitting parameters. The decay parameters are listed in Table 2. The decay rate of $\mathrm{Gd}_{0.20} \mathrm{Y}_{0.77} \mathrm{VO}_{4}: \mathrm{Sm}^{3+}$ is slower than that of $\mathrm{YVO}_{4}: \mathrm{Sm}^{3+}$, indicating that with the addition of $\mathrm{Gd}^{3+}$ ions an extra pathway is introduced in the energy transfer phenomenon, thereby enhancing the decay rate. Firstly, energy is transferred from $\mathrm{VO}_{4}{ }^{3-}$ to $\mathrm{Gd}^{3+}$; afterwards, this excitation energy is trapped by the dopant $\mathrm{Sm}^{3+}$ ions, which increases the $\mathrm{VO}_{4}{ }^{3-}$ overall decay rate. This further supports the role of $\mathrm{Gd}^{3+}$ ions as intermediates for efficient energy transfer from $\mathrm{VO}_{4}{ }^{3-}$ to $\mathrm{Sm}^{3+}$ (Wei et al., 2011)

\subsection{CIE colour coordinates}

The corresponding CIE (Commission Intemationale de I'Eclairage 1931 chromaticity) coordinate positions of $\mathrm{Gd}_{0.20} \mathrm{Y}_{0.77} \mathrm{VO}_{4}: \mathrm{Sm}^{3+}$ were calculated and are presented in Fig. 8. The CIE chromaticity coordinates were determined using PL data recorded at an interval of $1 \mathrm{~nm}$ which were fed into an in-house developed program based on the equidistant wavelength method (Kelmer, 1969). The corresponding values

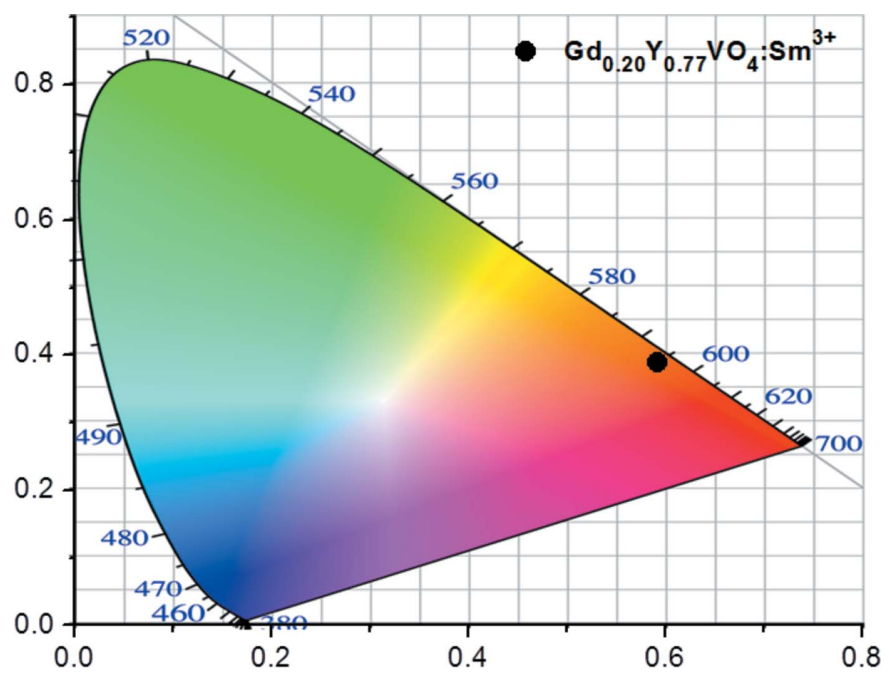

Figure 8

CIE diagram of the $\mathrm{Sm}^{3+}$ doped $\mathrm{Gd}_{0.20} \mathrm{Y}_{0.77} \mathrm{VO}_{4}$ nanophosphor showing the colorimetric coordinates. are $(x=0.59, y=0.38)$, which lies in the orange-red region, specifically where the spectral response of Si solar cells is significantly high.

\section{Conclusion}

In this work, $\mathrm{Sm}^{3+}$ doped $\mathrm{Gd}_{x} \mathrm{Y}_{1-x} \mathrm{VO}_{4}$ phosphors with different $\mathrm{Gd}$ concentrations ( $0-80 \mathrm{~mol} \%$ ) have been successfully synthesized by the chemical co-precipitation method. The XRD pattern and Rietveld analysis confirmed that the synthesized phosphor crystallizes in a single phase with a tetragonal structure. The role of $\mathrm{Gd}^{3+}$ ions as intermediates in emission enhancement has been successfully established with UV, PL and time-resolved PL decay measurements. The optical band gaps of $\mathrm{YVO}_{4}$ and $\mathrm{Gd}_{0.20} \mathrm{Y}_{0.77} \mathrm{VO}_{4}$ have been approximated from the UV-vis-NIR absorption spectra to be 3.75 and $3.50 \mathrm{eV}$, respectively. Under $311 \mathrm{~nm}$ excitation, the emission intensity of $\mathrm{Gd}_{0.20} \mathrm{Y}_{0.77} \mathrm{VO}_{4}: \mathrm{Sm}^{3+}$ phosphor is the highest, with the optimum $\mathrm{Gd}^{3+}(20 \mathrm{~mol} \%)$ and $\mathrm{Sm}^{3+}$ ( $3 \mathrm{~mol} \%$ ) concentration. The PL emission intensity of $\mathrm{Gd}_{0.20} \mathrm{Y}_{0.77} \mathrm{VO}_{4}: \mathrm{Sm}^{3+}$ is enhanced as compared to that of $\mathrm{YVO}_{4}: \mathrm{Sm}^{3+}$, for the optimized $\mathrm{Sm}^{3+}$ concentration. The combination of their unique features of high surface-tovolume ratios, monodispersion and optimum photoluminescence suggests that these nanophosphors will find many interesting applications in semiconductor photophysics, inorganic light-emitting diodes, solar cells and nanodevices.

\section{Funding information}

Funding for this research was provided by: Council of Scientific and Industrial Research (CSIR) (award Nos. 31/1(445)/ 2015-EMR-1, 31/1(448)/2015-EMR-1); Board of Research in Nuclear Sciences (BRNS) (award No. 34/14/16/2016-BRNS/ 34041).

\section{References}

Braga, A. F. B., Moreira, S. P., Zampieri, P. R., Bacchin, J. M. G. \& Mei, P. R. (2008). Solar Energy Mater. Solar Cells, 92, 418-424.

Chen, H. M., Chen, C. K., Liu, R. S., Zhang, L., Zhang, J. \& Wilkinson, D. P. (2012). Chem. Soc. Rev. 41, 5654-5671.

Chen, L., Chen, K. J., Hu, S. F. \& Liu, R. S. (2011). J. Mater. Chem. 21, 3677-3685.

Chen, X., Li, C., Grätzel, M., Kostecki, R. \& Mao, S. S. (2012). Chem. Soc. Rev. 41, 7909-7937.

Heng, C. L., Wang, T., Su, W. Y., Wu, H. C., Yin, P. G. \& Finstad, T. G. (2016). J. Appl. Phys. 119, 123105-123107.

Hisatomi, T., Kubota, J. \& Domen, K. (2014). Chem. Soc. Rev. 43, 7520-7535.

Juan, Y., Jian-Bei, Q., Yu-An, W. \& Da-Cheng, Z. (2014). Chin. Phys. $B, \mathbf{2 3}, 104224-104227$.

Kelmer, J. (1969). Luminescent Screens: Photometry and Colorimetry, p. 118. London: Iliffe.

Krumpel, A. H., van der Kolk, E., Cavalli, E., Boutinaud, P., Bettinelli, M. \& Dorenbos, P. (2009). J. Phys. Condens. Matter, 21, 115503-115508. 
Kumari, P. \& Manam, J. (2015). RSC Adv. 5, 107575-107584.

Liu, D., Shi, J., Tong, L., Ren, X., Li, Q. \& Yang, H. (2012). J. Nanopart. Res. 14, 1216-1223.

Liu, G., Hong, G., Wang, J. \& Dong, X. (2006). Nanotechnology, 17, 3134-3138.

Pinel, P., Cruickshank, C. A., Beausoleil-Morrison, I. \& Wills, A. (2011). Renewable Sustainable Energy Rev. 15, 3341-3359.

Ronde, H. \& Blasse, G. J. (1978). J. Inorg. Nucl. Chem. 40, 215219.

Shen, W. Y., Pang, M. L., Lin, J. \& Fang, J. (2005). J. Electrochem. Soc. 152, $\mathrm{H} 25-\mathrm{H} 28$.

Som, S., Kumar, V., Kumar, V., Gohain, M., Pandey, A., Duvenhage, M. M., Terblans, J. J., Bezuindenhoud, B. C. B. \& Swart, H. C. (2016). Ultrason. Sonochem. 28, 79-89.
Tian, Z., Liang, H., Han, B., Su, Q., Tao, Y., Zhang, G. \& Fu, Y. (2008). J. Phys. Chem. C, 112, 12524-12529.

Wang, J., Xu, Y., Hojamberdiev, M., Cui, Y., Liu, H. \& Zhu, G. (2009). J. Alloys Compd. 479, 772-776.

Wegh, R. T., Donker, H., Oskam, K. D. \& Meijerink, A. (1999). J. Lumin. 82, 93-104.

Wei, X., Liu, Y., Jiang, G., Chen, Y., Yin, M. \& Xu, W. (2011). J. Nanosci. Nanotechnol. 11, 9556-9561.

Yang, H. K., Moon, B. K., Choi, B. C., Jeong, J. H. \& Kim, K. H. (2011). CrystEngComm, 13, 4723-4728.

Zhydachevskii, Y., Lipińska, L., Baran, M., Berkowski, M., Suchocki, A. \& Reszka, A. (2014). Mater. Chem. Phys. 143, 622-628.

Zou, Z., Ye, J., Sayama, K. \& Arakawa, H. (2001). Nature, 414, 625627. 